\title{
Control of a Photovoltaic System Operating at Maximum Power Point and Constant Output Voltage under Different Atmospheric Conditions
}

\author{
Onur Deveci*, Coşku Kasnakoğlu \\ Department of Electrical and Electronics Engineering, TOBB University of Economics and Technology, \\ 06560, Ankara, Turkey. \\ * Corresponding author. Tel.: +90 312 2924000; email: odeveci@etu.edu.tr \\ Manuscript submitted February 17, 2015; accepted July 10, 2015. \\ doi: 10.17706/ijcee.2015.7.4.240-247
}

\begin{abstract}
This paper focuses on the design, modelling and MATLAB simulation of photovoltaic (PV) panel, DC/DC converters, maximum power point tracker (MPPT), battery, PID controllers and other control algorithms for constant DC voltage output PV system. Overall system is modelled and simulated with MATLAB/Simulink-SimPowerSystems toolbox which is specifically developed to simulate electrical power systems. Commonly used conventional linearization methods are not available for PID controller design for such a system having cascaded pulse width modulation (PWM) switching DC/DC converters causing high nonlinearity, forcing the use of a new alternative technique based on simulated input/output data. PV system is simulated under different atmospheric conditions with variable temperature and irradiation levels, system performance and efficiency is evaluated and it is observed that the designed controllers are capable to operate PV panel at its maximum power point under different atmospheric conditions and provide constant DC voltage to the load while charging the battery with excess power.
\end{abstract}

Key words: MPPT, PID control, PV system, voltage regulation.

\section{Introduction}

Conventional energy resources, expected to deplete in a near future unavoidably, take the first place in global energy production which cannot satisfy the need due to increasing population and industrialization. The gap between the energy production and consumption increases with each passing day [1]. Additional environmental problems arising from the production and consumption of conventional energy sources increased the interest in renewable energy sources worldwide; especially interest in PV systems has increased considerably in recent years. With the increase in research and development activities in photovoltaics, demand for PV systems has increased each year with an average of $20-25 \%$ in the last 20 years [2], [3].

The voltage and current values obtained from PV panels vary according to the load profile and atmospheric conditions [4], [5]. Consequently, the maximum power value that can be obtained from the PV panel varies depending on the atmospheric conditions. Through the use MPPT, higher energy conversion efficiency can be ensured with less PV panels and lower cost PV systems [6]. For such maximum power point tracking to improve efficiency and output voltage regulation; DC/DC converters, inverters and electric batteries can be used [7]. 
In this study, design and modelling of an MPPT controller to obtain maximum power from the PV panel, buck and boost DC/DC converters for output voltage regulation and battery charging to provide power for other DC loads connected to the system and PID controllers generating duty cycle for PWM switching DC/DC converters are performed. Overall system is simulated with MATLAB/Simulink-SimPowerSystems toolbox, results regarding the output voltage regulation and battery charging and future studies are discussed.

\section{Components of the PV System}

Main components that constitute the PV system and which are detailed in this section are shown in Fig. 1.

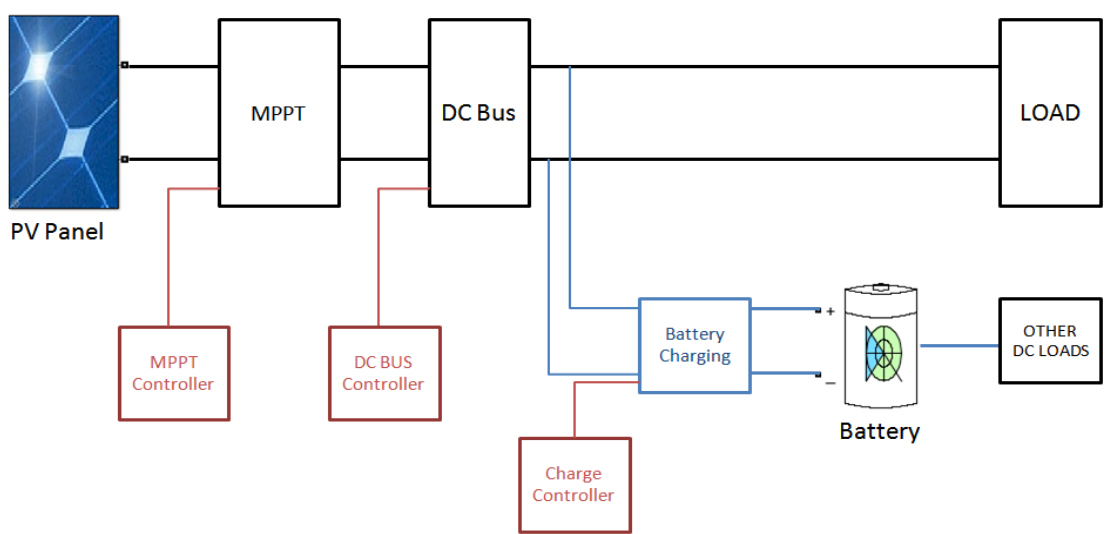

Fig. 1. Main components of the PV System.

\subsection{PV Panel}

In order to design and model the PV panel, design parameters regarding the PV system input and output, are determined as given in Table 1.

Table 1. Design Parameters Regarding the PV System

\begin{tabular}{lll}
\hline Design Parameter & Numerical Value & Unit \\
\hline Resistive Load & $5 \pm 20 \%$ & $\Omega$ \\
Required Output Voltage & $12 \pm 5 \%$ & $\mathrm{~V}$ \\
Irradiation Level & $600-1000$ & $\mathrm{~W} / \mathrm{m}^{2}$ \\
Temperature Level & $20-30$ & ${ }^{\circ} \mathrm{C}$ \\
Resistive Load & $5 \pm 20 \%$ & $\Omega$ \\
\hline \hline
\end{tabular}

Taking 20\% tolerance on the resistive load as a design parameter, maximum and minimum power required by the load is $P_{\text {load, } \min }=39.7 \mathrm{~W}$ and $P_{\text {load, } \min }=21.7 \mathrm{~W}$.

For selecting the appropriate size for the PV panel, DC/DC converter losses, reverse current protecting diode losses and control switch (MOSFETs) losses shall be taken into account. It is also important if the PV panel can meet the maximum power need of the load at the lowest irradiation level and lowest outside temperature. In this study, technical parameters of STP080S 80W PV panel of SunTech are used.

Taking into account of the temperature and irradiation effects on the output current of a solar cell, PV array output current can be calculated with (1) [8].

$$
I_{p v}=N_{p} I_{p h}-N_{p} I_{s}\left(e^{\frac{q\left(V+I_{p v} R_{s}\right)}{a K T}}-1\right)-\frac{1}{R_{s h}}\left(\frac{V}{N_{s}}+\frac{I_{p v} R_{s}}{N_{p}}\right)
$$


$R_{s}$ is the series resistance in the cell model, $R_{s h}$ is the shunt resistance in the cell model, $I_{p h}$ is the light generated current, $I_{S}$ is the reverse saturation current of the diode, $q$ is the electron charge, $a$ is the diode ideality factor, $T$ is the temperature in degrees Kelvin, $N_{s}$ is the number of solar cells connected in series and $N_{p}$ is the number of solar panels connected in parallel in the array.

Fig. 2 provides P-V plots for the chosen STP080S PV panel. As stated above, PV panel shall meet the maximum power need of the load when the irradiation and temperature is lowest. As given in Table 1, lowest irradiation value is $600 \mathrm{~W} / \mathrm{m}^{2}$ and the temperature value is $20^{\circ} \mathrm{C}$. From Fig. 2, maximum output power generated by the PV panel at these conditions is $46.5 \mathrm{~W}$ which is $17 \%$ larger than the maximum load power $39.7 \mathrm{~W}$. So it is proven that STP080S PV panel can be utilized to meet the load power requirements at all atmospheric conditions defined in Table 1.
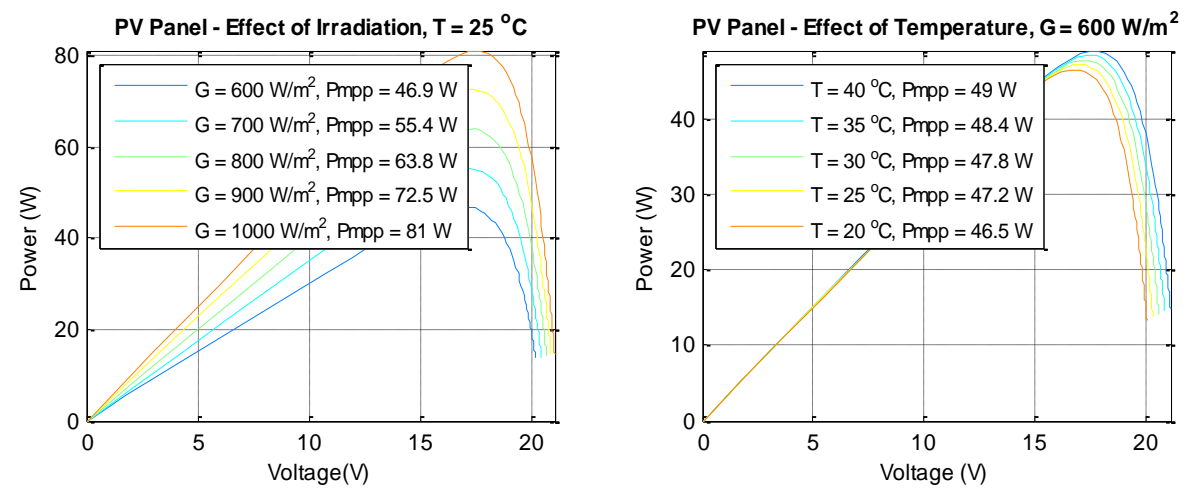

Fig. 2. Power-Voltage plots of STP080S.

\subsection{Converters}

Buck and boost converters used in the PV system are described in this section.

\subsubsection{Buck converters}

Panel output voltage is between 16-18 VDC for obtaining the maximum power from the PV panel but 12 VDC is required at the output which necessitates the use of a buck converter to reduce the panel voltage during the maximum power point tracking. Also for battery charging, in order to decrease the 12 VDC bus voltage into the required 6 VDC battery voltage buck converter is used. Equation (2) is used to determine $L_{\min }$ and $C_{\min }$ [9]. Selected inductance and capacitance values used for the converter design are some multiples of minimum values for decreasing the current and voltage ripples for smaller losses and better control.

$$
L_{\min }=\frac{\left(1-D_{\min }\right) V_{\text {out }}}{2 f_{s} I_{\text {out }}} \quad C_{\min }=\frac{\left(1-D_{\min }\right)}{8 L_{\min } \frac{\Delta V_{0}}{V_{0}} f_{s}^{2}}
$$

$D_{\min }$ is the minimum duty cycle that can be provided to the converters which is $5 \%$ for this study, $R$ is the resistive load resistance $(\Omega)$ which is $6 \Omega$ to obtain the highest required inductance, $f_{s}$ is the switching frequency $(\mathrm{Hz})$ which is $100 \mathrm{kHz}$ for this study and $\Delta V_{0} / V_{0}=0.01$ which means $1 \%$ voltage ripple.

\subsubsection{Boost converters}

Panel output voltage is between 16-18 VDC for obtaining the maximum power from the PV panel but 12 VDC is required at the output which necessitates. MPPT buck converter forces the PV panel to operate 
always at the maximum power point but the output of the converter decreases well below the required 12 VDC. Also both for supplying always 12 VDC to the load and constant charging current or voltage for the battery, there is a need for a 12 VDC bus which is composed of a boost converter. The reason for not using buck-boost converter, Cúk converter and Sepic converter is their lower efficiencies when compared to buck and boost converters, high ripple currents at the output of the buck-boost converter causing high noises and high complexity and cost of the Cúk converter [10].

Equation (3) is used to determine $L_{\min }$ and $C_{\min }$ [9]. Selected inductance and capacitance values used for the converter design are some multiples of minimum values for decreasing the current and voltage ripples for smaller losses and better control.

$$
L_{\min }=\frac{D_{\text {opt }}\left(1-D_{\text {opt }}\right)^{2} V_{\text {out }}}{2 f_{s} I_{\text {out }}} \quad C_{\text {min }}=\frac{I_{\text {out }} D_{\text {max }}}{V_{\text {out }} \frac{\Delta V_{0}}{V_{0}} f_{s}}
$$

$D_{\max }$ is the maximum duty cycle $95 \%, D_{\text {opt }}$ is the optimum duty cycle which gives the minimum inductance, $50 \%, f_{s}$ is the switching frequency $(\mathrm{Hz})$ which is $100 \mathrm{kHz}$ for this study, $\Delta V_{0} / V_{0}=0.01$ which means $1 \%$ voltage ripple.

\subsection{Controllers}

In this section, MPPT controller, DC Bus boost converter PID controller and battery charger controllers used in the PV system are described.

\subsubsection{MPPT controller}

In order to operate PV panel at maximum power point under various temperature and solar radiation, maximum power tracking methods are used. In this study, two commonly used MPPT techniques, Perturb \& Observe (P\&O) and Incremental Condutance (IC), are investigated.

$\mathrm{P} \& \mathrm{O}$ algorithm is based on making small changes in the PV panel terminal voltage in each control period and observing the change in the output power $(\Delta P)$. If $\Delta P>0$, panel voltage is increased; if $\Delta P<0$ panel voltage is decreased and panel operating point is approached to the maximum power point [11]. P\&O is an easy and practical method during the applications but since in each period panel voltage is perturbed, system oscillates around the required operating point $\Delta P=0$. At low solar radiation levels, P-V graph of the solar panel is more flat which makes $\mathrm{P} \& 0$ algorithm to find the maximum power point more difficult. These drawbacks of the $\mathrm{P} \& O$ algorithm triggered the use of IC method which yields better results in operating at maximum power point and rapidly changing weather conditions [12].

According to the IC method, slope $(\mathrm{dP} / \mathrm{dV})$ of the panel $\mathrm{P}-\mathrm{V}$ graph is analysed. $\mathrm{dP} / \mathrm{dV}$ is zero at maximum power point, negative at the right hand side and positive at the left hand side of the maximum power point.

In this study, MPPT controller is built in MATLAB/Simulink with an IC algorithm implemented in the Stateflow-Chart block to obtain maximum power from the PV panel.

\subsubsection{DC bus boost converter PID controller}

In order to create a 12 VDC bus for the load and the battery at the output of the PV system; boost converter is used as previously indicated.

Since there are two-level and three-level cascaded converters and PWM driven switches in the system, it is difficult to design the PID controllers theoretically. Attempts were made to design these controllers numerically (using 'Tune' option for 'Discrete PID Controller' block of Simulink) but due to high nonlinearities this approach resulted in a zero system and failed. We have therefore employed an alternative linearization method based on bringing the system to a typical operating point using the system 
input and then providing a step change around this point, the data from which is used in the linearization procedure. (In MATLAB/Simulink this can be carried out using steps: Plant $\rightarrow$ Identify New Plant $\rightarrow$ Plant Identification $\rightarrow$ Get I/O Data $\rightarrow$ Simulate Data $\rightarrow$ Simulate I/O Data, the results of which can be seen in Fig. 3.) Using predefined control structures such as one pole, two real poles, state-space model and underdamped pair + real pole, controlled system data is fitted into the identification data on the graph. When these two data fit well, P, I, D and filter coefficients are generated automatically by the software, which are then fine tuned manually for improved response speed and robustness.

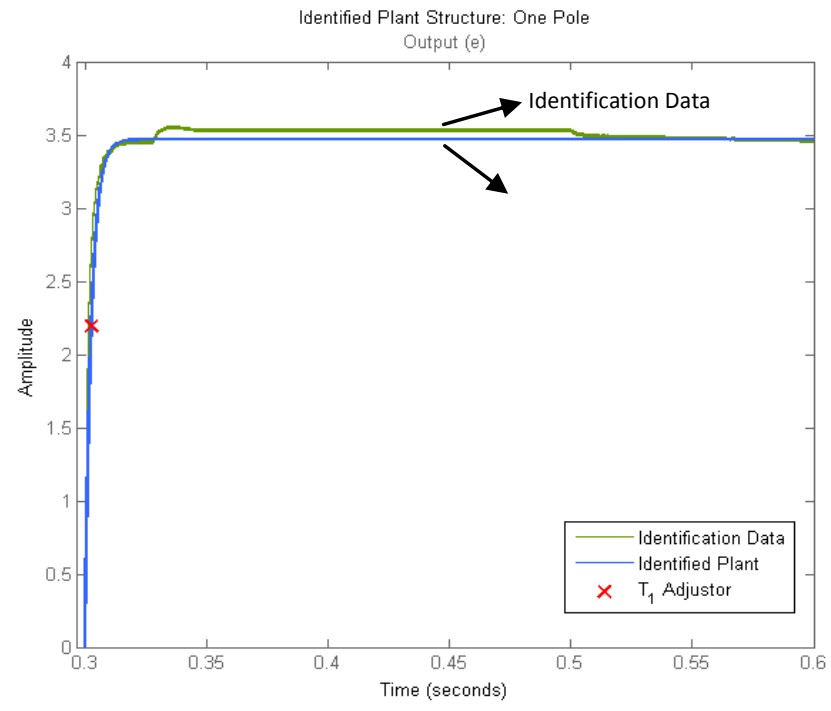

Fig. 3. Identification data and the identified plant.

\subsubsection{Battery charger controllers}

In order to appropriately charge the battery with excess power from the PV panel, battery charging controllers are used.

Since the DC Bus in the system behaves like a current-limited constant voltage source, a lithium-ion battery is used in the PV system. Its low maintenance requirement, low self-discharge rate and very high energy density are also other advantages which are taken into account for such a solar system design [13]. For typical Li-Ion battery, constant current charging is required up to a certain value of the battery (fully charged voltage value) and then charge current is decreased and battery is charged with constant voltage to always keep it at full charge. For numerical simulations Battery block under SimPowerSystems is used in the model, which allows for one to select the battery type and enter basic data (e.g. capacity, nominal voltage, initial state of charge) and the block automatically calculates other necessary data.

Battery charging circuit including the controller decides on whether to constant current charge, constant voltage charge or shutting down the switch to isolate battery from the rest of the system. Constant voltage and constant current charging PID controllers are separately built inside the battery charger controller and they have the same structure and designed with the same procedure by obtaining identification data during real-time simulation as previously indicated.

\section{Results, Discussion and Future Works}

The final model of the whole system is built in MATLAB/Simulink environment, after the completion of the design and modelling of all subsystems of PV system. Standard models of the power diodes (to prevent reverse currents), MOSFETs (used inside the converters and used as cut-off switch) and voltage and current ripples filtering capacitors and inductors are used in SimPowerSystems for more realistic simulation as 
given in Fig. 4.

Variable temperature $\left(20-30{ }^{\circ} \mathrm{C}\right)$ and irradiation levels $\left(600-1000 \mathrm{~W} / \mathrm{m}^{2}\right)$ are applied to the PV panel and the controlled output voltage is obtained as given in Fig. 5.

It is observed from Fig. 5 that the output voltage on the load is controlled within maximum deviation of $1 \%$ at $600 \mathrm{~W} / \mathrm{m}^{2}$ and $20^{\circ} \mathrm{C}$ which is much lower than the required $5 \%$ tolerance indicated in Table 1 and verifies the design of the PID controllers and other subsystems. Using real models of the circuit components during the simulation causes the unexpected voltage values between $t=0$ and $t=0.03$ seconds. Also ,in practice, temperature and irradiation values do not change suddenly as given in Fig. 5 which explains the increase in output voltage when irradiation and temperature changes at $t=0.2$ and $t=0.3$ seconds. These voltage spikes are expected to be smaller in real implementation.

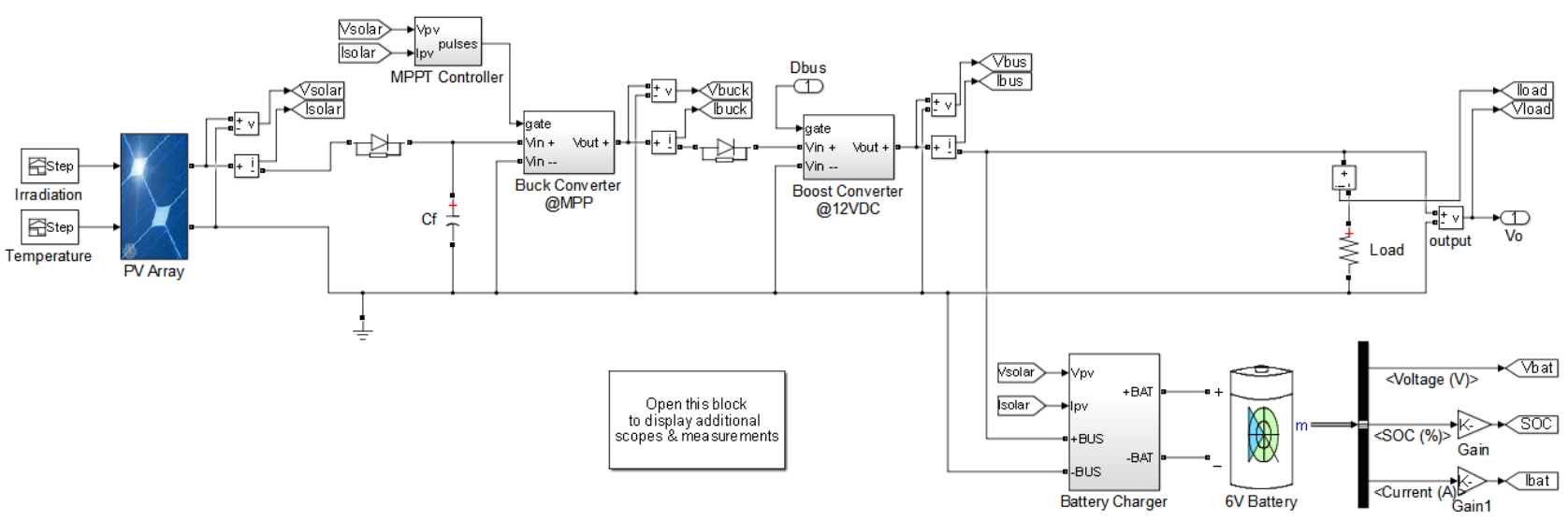

Fig. 4. PV system in MATLAB/Simulink.

Also other objective of the system to operate PV panel always at maximum power point is performed and more than $80 \%$ of the power produced by PV panel is captured by the battery and load which ensures the maximum utilization of the solar energy captured.
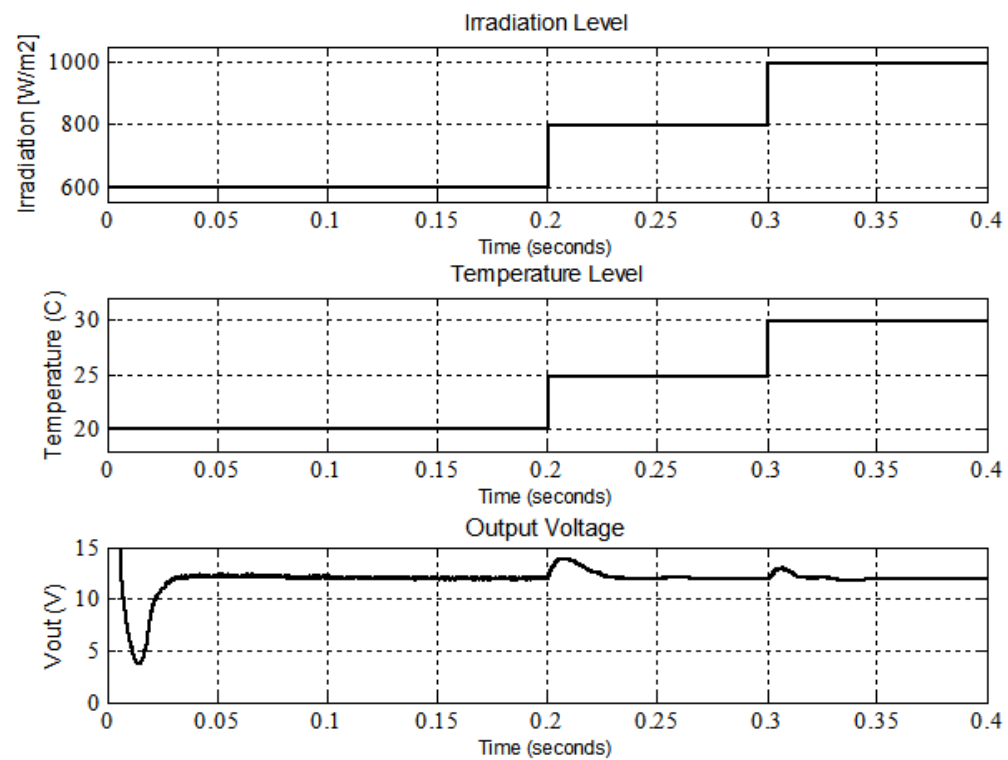

Fig. 5. Ambient temperature/irradiation changes and controlled output voltage.

For future research, it is planned to decrease the controlled output voltage ripple, increase the excess power captured by the battery, comparing system performance by using different MPPT and control 
techniques, operating the PV system within a broader temperature and irradiation profile by using gain scheduling and implementing a real system and comparing it with the simulation. Also cascaded PID controller will be utilized to generate reference current and voltage values for battery charging to increase the ratio of the captured power above $90 \%$.

\section{References}

[1] Kadıglu, S., \& Tellioglu, Z. (1996). Enerji kaynaklarının kullanımı ve çevreye etkileri. Proceedings of the TMMOB Turkish Energy Symposium (pp. 55-67).

[2] Linares, L., Erickson, R. W., MacAlpine, S., \& Brandemuehl, M. (2009). Improved energy capture in series string photovoltaics via smart distributed power electronics. Proceedings of 24th IEEE Applied Power Electronics Conference and Exposition (pp. 904-910).

[3] Selvaraj, J., \& Rahim, N. A. (2009). Multilevel inverter for grid-connected PV system employing digital PI controller. IEEE Transactions on Industrial Electronics, 56(1), 149-158.

[4] Hussein, K. H., Muta, I., Hoshino, T., \& Osakada, M. (1995). Maximum photovoltaic power tracking: An algorithm for rapidly changing atmospheric conditions. IEEE Proceedings on Generation, Transmission and Distribution, 142(1), 59-64.

[5] Liu, X., \& Lopes, L. A. C. (2004). An improved perturbation and observation maximum power point tracking algorithm for PV arrays. IEEE Proceedings of 35th Power Electronics Specialists Conference: Vol. 3 (pp. 2005-2010).

[6] Enrique, J. M., Duran, E., Sidrach-de-Cardona, M., \& Andujar, J. M. (2007). Theoretical assessment of the maximum power point tracking efficiency of photovoltaic facilities with different converter topologies. Solar Energy, 81, 31-38.

[7] Demirtas, M., Sefa, I., Irmak, E., \& Colak, I. (2008). Güneş Enerjili Sistemler için Mikrodenetleyici Tabanlı DA/DA Yükselten Dönüştürücü. Journal of Gazi Univ. Muh. Mim. Fakultesi., 23(3), 719-728.

[8] Kim, I., Kim, M., \& Youn, M. (2006). New maximum power point tracker using sliding-mode observer for estimation of solar array current in the grid-connected photovoltaic system. IEEE Transactions on Industrial Electronics, 53(4), 1027-1035.

[9] Mohan, N., Undeland, T., \& Robbins, W. P. (2003). Power Electronics: Converters, Applications and Design. John Wiley \& Sons.

[10] Walker, G., \& Sernia, P. (2004). Cascaded DC-DC converter connection of photovoltaic modules. IEEE Transactions on Power Electronics, 19(4), 1130-1139.

[11] Yafaoui, A., Wu, A. B., \& Cheung, R. (2007). Implementation of maximum power point tracking algorithm for residential photovoltaic systems. Proceedings of 2nd Canadian Solar Building Conference.

[12] Brito, M., Sampaio, L., Luigi, G., et al. (2011). Comparative analysis of MPPT techniques for PV applications. Proceedings of IEEE International Conference on Clean Electrical Power (pp. 99-104).

[13] Park, H., Kim, C., Kim, B., Moon, G., \& Lee, J. (2007). Modularized charge equalization with high power density and low voltage stress for HEV lithium-ion battery string. Proceedings of 7 th IEEE International Conference on Power Electronics (pp. 784-789).

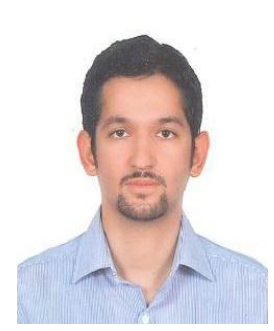

Onur Deveci obtained the B.Sc. degree in electrical and electronics engineering from Middle East Technical University, Ankara, Turkey in 2007, and the M.Sc. degree in sustainable development, energy and management from University of Salford, Manchester, UK in 2009. He is now working towards his Ph.D. degree in electrical and electronics engineering at TOBB University of Economics and Technology, Ankara, Turkey. 
Since 2010, he has been with the Aselsan Inclusive, Ankara, Turkey, where he is currently an expert engineer in homeland security systems program management.

Mr. Deveci's current research interests include solar power, wind power, linear/nonlinear control and power electronics.

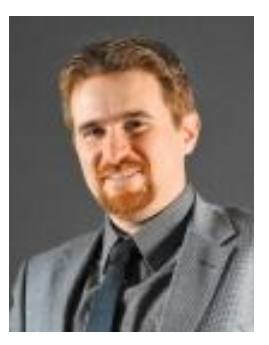

Coşku Kasnakoğlu obtained the B.Sc. degree from the Department of Electrical and Electronics Engineering and the Department of Computer Engineering at the Middle East Technical University (METU), Ankara, Turkey in 2000. He obtained his M.Sc. and Ph.D. degrees from the Department of Electrical and Computer Engineering at the Ohio State University (OSU), Columbus, Ohio, USA in 2003 and 2007, respectively.

From 1996 to 2000, he worked as a researcher at the Turkish Scientific Council (TUBITAK), Information Technologies and Electronics Research Institute (BILTEN). From 2000 to 2007, he worked as a graduate researcher at OSU and in 2008 he joined TOBB University of Economics and Technology, where he is currently an associate professor in the Department of Electrical and Electronics Engineering.

Dr. Kasnakoglu's current research interests include nonlinear control, flow control, unmanned air vehicles, dynamical modeling, adaptive control and linear parameter varying systems. He is a member of IEEE, AIAA, IACSIT and has published numerous scientific papers in respected journals and conferences. 